\title{
TSH controls Ref-1 nuclear translocation in thyroid cells
}

\section{G Tell $^{1}$, L Pellizzari ${ }^{1}$, C Pucillo $^{1}$, F Puglisi ${ }^{2}$, D Cesselli $^{2}$, M R Kelley ${ }^{3}$, C Di Loreto ${ }^{2}$ and $G$ Damante ${ }^{1}$}

\author{
${ }^{1}$ Dipartimento di Scienze e Tecnologie Biomediche, Università di Udine, Udine, Italy \\ ${ }^{2}$ Istituto di Anatomia Patologica, Università di Udine, Udine, Italy \\ ${ }^{3}$ Department of Pediatrics, Section of Hematology/Oncology, H B Wells Center for Pediatrics Research, \\ Indiana University School of Medicine, Indianapolis, Indiana, USA
}

(Requests for offprints should be addressed to G Damante, Dipartimento di Scienze e Tecnologie Biomediche, Università di Udine-Piazzale Kolbe, 1-33100 Udine, Italy;

Email: GDamante@makek.dstb.uniud.it)

\begin{abstract}
Ref-1 (called also APE) is a bifunctional protein playing a role in a large variety of cell functions. It is a major member of the DNA base excision repair system. Moreover, through reduction of cysteine residues, Ref-1 controls the activity of several transcription factors. It has been previously demonstrated that TSH up-regulates Ref-1 gene expression in thyroid cells. By using the rat FRTL-5 cell line, we demonstrate that TSH controls Ref-1 intracellular localization. Western blot experiments indicate that addition of TSH to the culture
\end{abstract}

medium increases the Ref-1 cytoplasm-to-nucleus translocation. This phenomenon occurs at early times of TSH stimulation and is not dependent on protein neosynthesis. The Ref- 1 cellular compartmentalization was also investigated in human thyroid tumors. A Ref-1 nuclear/cytoplasmic ratio difference between normal and cancerous thyroid tissues was observed. These results suggest that Ref-1 localization may have a critical role in the control of thyroid cell functions.

Fournal of Molecular Endocrinology (2000) 24, 383-390

\section{INTRODUCTION}

Ref-1, also called APE, is a protein having both apurinic/apyrimidinic endonuclease DNA repair activity and nuclear redox activity (Nakamura et al. 1997, Rothwell et al. 1997). This protein plays a fundamental role in DNA base excision repair and its activity is considered as the rate-limiting step in DNA repair due to oxidative damage (Ramana et al. 1998). By means of the redox activity, Ref-1 is able to control the DNA-binding function of several transcription factors, including $\mathrm{AP}-1, \mathrm{NF}-\kappa \mathrm{B}$, ATF/CREB and Pax proteins. (Xanthoudakis et al. 1992, Tell et al. 1998a). Recent developments have also intimately linked Ref-1 as a major controlling factor for p53 activity through a redox mechanism (Jayaraman et al. 1997) and have established its functional interaction with $\mathrm{p} 53$ in vivo (Meira et al. 1997, Gaiddon et al. 1999). There are several pieces of evidence demonstrating the biological relevance of Ref-1. The down-regulation of Ref-1 protein levels, through antisense techniques, increases DNA damage in cells treated with various agents
(Walker et al. 1994). The Ref-1 gene inactivation in mice is lethal at early stages of embryonic development (Xanthoudakis et al. 1996). Both DNA repair mechanisms and some of the transcription factors regulated by Ref- 1 are heavily involved in the generation/progression of human cancer. Thus, it could be conceivable that Ref-1 may have a role during neoplastic transformation.

Since Ref-1 controls the binding activity of a large variety of transcription factors, it could represent an important device for regulation of gene expression. Accordingly, Ref-1 protein is up-regulated by non-toxic levels of a variety of reactive oxygen species (ROS) such as superoxide anion $\left(\mathrm{O}_{2}\right), \mathrm{H}_{2} \mathrm{O}_{2}$ and the hydroxyl radical $(\mathrm{OH})$, which can be generated by external agents such as ionizing radiation (Ward 1994). Moreover, ROS can be produced during pathological states in activated neutrophils and by treating cells with cytokines such as tumor necrosis factor- $\alpha$ and interleukin- $1 \beta$ (Schreck et al. 1991). Ref-1 up-regulation induced by ROS is due to translational mechanisms, being blocked by the treatment of cells with 
cycloheximide (Ramana et al. 1998). Ref-1 is subjected to hormonal control; in thyroid cells Ref-1 protein is up regulated by thyrotropin (TSH) (Asai et al. 1997). The regulation of transcription factors by Ref- 1 occurs through a post-translational mechanism (reduction of cysteine residues) that operates upon preformed proteins and that, therefore, is much faster than mechanisms acting through protein neosynthesis. From a regulatory point of view, these data generate an apparent paradox. In fact external stimuli, such as cytokines or TSH, would activate a fast mechanism of gene expression regulation (reduction of cysteine residues in DNA-binding domains of transcription factors) by a time-consuming event such as the neosynthesis of the regulator (Ref-1).

Based on these considerations, the focus of our investigation was to test whether TSH controls Ref-1 activity by mechanisms different from protein neosynthesis. We demonstrate that TSH increases the Ref-1 cytoplasm-to-nucleus translocation suggesting that the cell localization of this protein may define different functional states of the thyroid cell. For these reasons the Ref- 1 cellular localization in human thyroid tumors was investigated. A Ref-1 nuclear/cytoplasmic ratio difference between normal and cancerous thyroid tissues was observed.

\section{MATERIALS AND METHODS}

\section{Rat FRTL-5 cell culture and cell fractionation}

FRTL-5 cells were cultured as described (Ambesi-Imbiombato \& Coon 1979). Cell nuclear extracts were prepared as previously described (Tell et al. 1998a). Briefly, $10^{7}$ cells were washed once with PBS and resuspended in $500 \mu \mathrm{l}$ hypotonic lysis buffer A $(10 \mathrm{mM}$ Hepes, $10 \mathrm{mM} \mathrm{KCl}, 0 \cdot 1 \mathrm{mM}$ $\mathrm{MgCl}_{2}, 0 \cdot 1 \mathrm{mM}$ EDTA, $2 \mu \mathrm{g} / \mathrm{ml}$ leupeptin, $2 \mu \mathrm{g} / \mathrm{ml}$ pepstatin, $0.5 \mathrm{mM}$ polymethylsulfonyl fluoride (PMSF), pH 7.9). After $10 \mathrm{~min}$, cells were homogenized by ten strokes with a loose-fitting Dounce homogenizer. Nuclei were collected by centrifugation for $5 \mathrm{~min}$ at $500 \mathrm{~g}$ at $4{ }^{\circ} \mathrm{C}$ in a microcentrifuge. The supernatant obtained after this centrifugation was considered as the cytoplasmic fraction. Nuclear proteins were extracted with $100 \mu \mathrm{l}$ buffer B $(10 \mathrm{mM}$ Hepes, $400 \mathrm{mM} \mathrm{NaCl}$, $1.5 \mathrm{mM} \mathrm{MgCl}_{2}, 0 \cdot 1 \mathrm{mM}$ EDTA, $2 \mu \mathrm{g} / \mathrm{ml}$ leupeptin, $2 \mu \mathrm{g} / \mathrm{ml}$ pepstatin, $0.5 \mathrm{mM}$ PMSF, $\mathrm{pH} 7 \cdot 9)$. After incubating for $20 \mathrm{~min}$ at $4{ }^{\circ} \mathrm{C}$, samples were centrifuged at $12000 \boldsymbol{g}$ at $4{ }^{\circ} \mathrm{C}$ for $15 \mathrm{~min}$. Nuclear and cytoplasmic extracts were then quantitated for protein levels (Bradford 1976) and used immediately for Western blot analysis or kept at $-80{ }^{\circ} \mathrm{C}$.

\section{Western blot analysis}

Twenty micrograms nuclear or cytoplasmic extracts, obtained from FRTL-5 cells incubated under different conditions, were electrophoresed in a $10 \%$ SDS-PAGE. Then proteins were transferred to nitrocellulose membranes (Schleicher \& Schuell, Keene, NH, USA). After transfer, membranes were saturated by incubation, at $4{ }^{\circ} \mathrm{C}$ overnight, with $10 \%$ non-fat dry milk in PBS $/ 0.1 \%$ Tween-20 and then incubated with the rabbit anti-Ref-1 antibody for $60 \mathrm{~min}$ at room temperature (RT). The Ref-1 affinity-purified polyclonal antibody was used as previously described (Xu et al. 1997). After three washes with PBS/0.1\% Tween-20, membranes were incubated with an anti-rabbit immunoglobulin coupled to peroxidase (Sigma Chemical Co., St Louis, MO, USA). After 60 min incubation at RT the membranes were washed several times with PBS $/ 0 \cdot 1 \%$ Tween-20 and the blots were developed using an enhanced chemiluminescence procedure (ECL; Amersham Pharmacia Biotech, Arlington Heights, IL, USA).

\section{Tissue samples}

Twenty-three formalin-fixed, paraffin-embedded thyroid tissue samples were evaluated for the expression of Ref-1 protein using an immunoperoxidase technique.

Tissue samples included four cases of follicular adenomas, five of papillary carcinoma, five of follicular carcinoma and four of undifferentiated carcinoma. The surrounding unaffected tissues from five cases of follicular adenomas were obtained as representative specimens of normal thyroid. Representative blocks of each case were selected for immunohistochemical staining.

\section{Immunohistochemistry}

Immunohistochemical detection of Ref-1 protein was performed by the avidin-biotin-peroxidase (ABC) method (Vectastain ABC Elite Kit; Vector, Burlingame, CA, USA), using a polyclonal antiRef-1 antibody produced at a 1:50 dilution.

The sections were freshly cut immediately before immunostaining, and placed on glass slides coated with 3-aminopropyltriethoxysilane. After deparaffinization by sequential passages through xylene, graded ethanol, and deionized water, the sections were boiled in $0 \cdot 1 \mathrm{M}$ citrate buffer, $\mathrm{pH} 7 \cdot 3$, in a $750 \mathrm{~W}$ microwave oven set at maximum power for $2 \mathrm{~min}$ and at $210 \mathrm{~W}$ for $8 \mathrm{~min}$. The sections were incubated with the above antibodies for $60 \mathrm{~min}$ at RT, then incubated with a secondary biotinylated antibody for $30 \mathrm{~min}$ at $\mathrm{RT}$, followed by $\mathrm{ABC}$ 
reagent for $30 \mathrm{~min}$ at $\mathrm{RT}$. The reaction product was detected with 3,3'-diaminobenzidine (Sigma). The sections were counterstained with hematoxylin. For negative controls, the primary antibody was omitted and replaced with rabbit immunoglobulins (Dako, Denmark). Cells were considered Ref-1-positive when brown staining of the nucleus and/or the cytoplasm was identified. One thousand cells for each case were evaluated by determining the nuclear/cytoplasmic positivity.

\section{RESULTS}

\section{Hormonal control of Ref-1 cytoplasm-to-nucleus translocation}

In normal thyroid cells Ref-1 is localized in both the cytoplasm and nuclear compartments (Kakolyris et al. 1998). We decided to test, therefore, if the Ref-1 cytoplasm-to-nucleus translocation is controlled by TSH in thyroid cells. The thyroid FRTL-5 cell line was used (Ambesi-Imbiombato \& Coon 1979). The relative amount of Ref-1 protein was assayed by Western blot analysis after the separation of nuclear and cytoplasm compartments. Fig. 1A shows the Ref-1 signal detected in cytoplasm or nucleus in cells cultured: (i) in the presence of TSH $(1 \mathrm{mU} / \mathrm{ml})$; (ii) in the absence of TSH for 5 days; and (iii) in cells cultured in the absence of $\mathrm{TSH}$ for 5 days and then hormonally stimulated for 1,3 and $6 \mathrm{~h}$. Signals from several experiments have been quantitated by scanning densitometry and results are shown in Fig. 1B. Cells cultured in the presence of TSH showed a strong Ref-1 signal in both the nuclear and cytoplasmic fraction. In the absence of TSH, Ref-1 levels decreased in both fractions but the reduction was much more evident in the cytoplasmic fraction. Compared with unstimulated cells, after $1 \mathrm{~h}$ of TSH treatment, an increase in the nuclear Ref-1 was detected, and it was associated with a reduction in the cytoplasmic fraction. After 3 or $6 \mathrm{~h}$ of TSH treatment the amount of nuclear Ref-1 was similar to that detected after $1 \mathrm{~h}$ of TSH stimulation. On the contrary, Ref-1 cytoplasmic levels at these late times were much more increased compared with those observed after $1 \mathrm{~h}$. These results suggest that the most significant effect, at early times of TSH stimulation, is an accelerated rate of Ref-1 cytoplasm-to-nucleus translocation. Only at late times ( 3 and $6 \mathrm{~h}$ ) is the TSH effect on Ref-1 neosynthesis significant. Due to this two-stage mode of stimulation by TSH, one would predict that an increase of nuclear Ref-1 levels upon TSH addition should be observed in conditions of blocked protein synthesis. In order to verify this
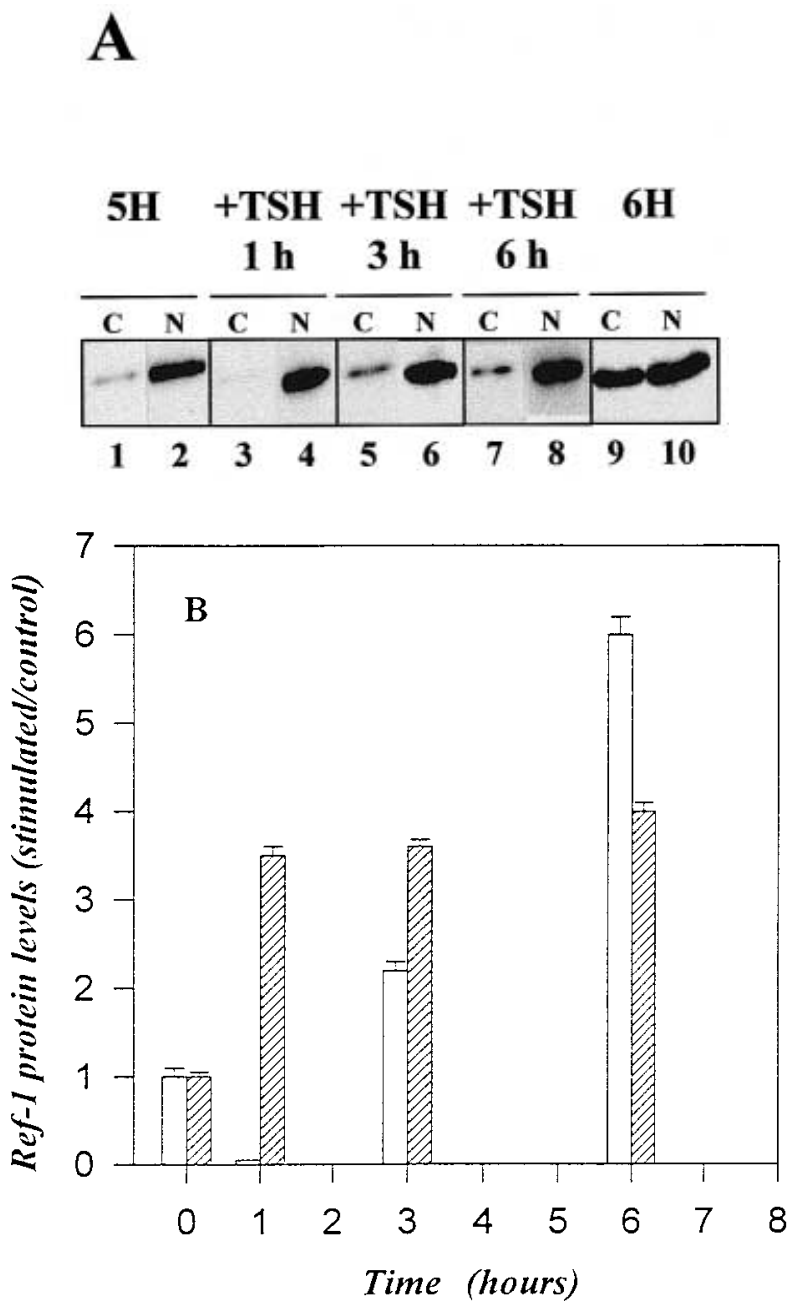

FIGURE 1. Hormonal control of Ref-1 cytoplasm-tonucleus translocation. (A) FRTL-5 cells were cultured in the absence of $\mathrm{TSH}(5 \mathrm{H})$ for 5 days (lanes 1 and 2$)$, in the presence of $1 \mathrm{mU} / \mathrm{ml}$ of $\mathrm{TSH}$ for different times ranging from 1 to $6 \mathrm{~h}$ (lanes 3-8), and constitutively treated with TSH $(6 \mathrm{H})$ without starvation (lanes 9,10$)$. The cells were then processed to obtain cytoplasmic (' $\mathrm{C}$ ', odd lanes) and nuclear ('N', even lanes) extracts. Twenty micrograms of each extract were loaded onto an SDS-PAGE for Western blot analysis with anti-Ref-1 polyclonal antibody and detected by ECL. (B) Values obtained from densitometric scanning of bands from several experiments are shown as the ratio between the Ref- 1 protein levels measured in cells treated with TSH (stimulated) and in untreated cells (control). Open columns represent the cytoplasmic Ref-1 protein levels and hatched columns the nuclear fractions. Bars indicate the mean value+s.D. of at least three independent experiments.

prediction, time-course experiments were run in the presence of cycloheximide, resembling conditions of blocked protein synthesis. As shown in Fig. 2, TSH 
A
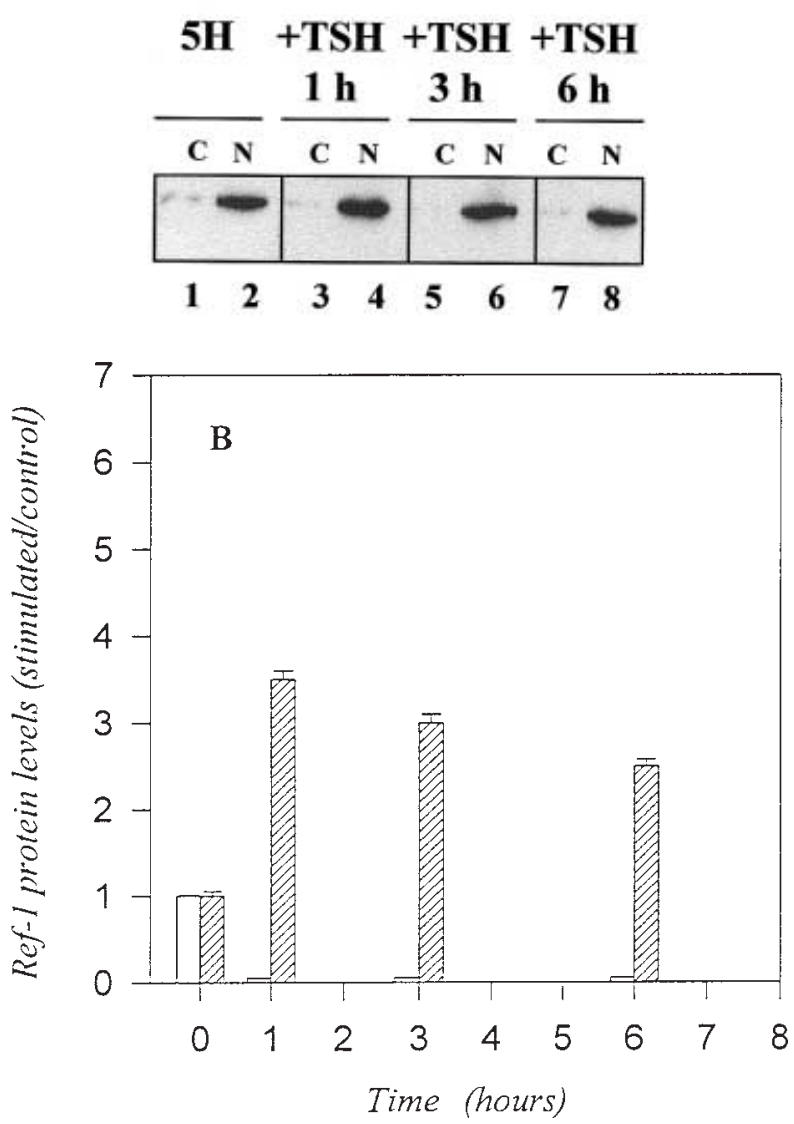

FIGURE 2. Cycloheximide pre-treatment of FRTL-5 cells does not prevent Ref-1 translocation into the nucleus after TSH treatment. (A) FRTL-5 cells were preincubated in the presence of the protein synthesis inhibitor cycloheximide $(10 \mu \mathrm{g} / \mathrm{ml})$ for $1 \mathrm{~h}$ before exposure to TSH. The cells were then processed to obtain cytoplasmic ('C', odd lanes) and nuclear ('N', even lanes) extracts. Twenty micrograms of each extract were loaded onto an SDS-PAGE for Western blot analysis with anti-Ref-1 polyclonal antibody. $5 \mathrm{H}$ indicates FRTL-5 cells cultured in the absence of TSH for 5 days. (B) Values obtained from densitometric scanning of bands from experiments of panel (A) are reported as the ratio between the Ref- 1 protein levels measured in cells treated with TSH (stimulated) and in untreated cells (control). Open columns represent the cytoplasmic Ref-1 protein levels and hatched columns the nuclear fractions. Bars indicate the mean value+s.D. of at least three independent experiments.

stimulation was still able to increase nuclear Ref-1 levels. Cytoplasmic Ref-1 levels were decreased, as expected since TSH stimulates Ref-1 cytoplasm-tonucleus translocation but it was not able to increase Ref-1 protein synthesis (due to the presence of cycloheximide). Therefore, we were able to dissociate the TSH effect due to cytoplasm-to-nucleus translocation from that due to novel protein synthesis.

\section{Ref-1 immunostaining of human thyroid tissues}

The observation that the Ref-1 cellular localization is regulated by TSH suggests that the difference in compartmentalization of this protein may have a biological relevance. In order to corroborate this statement, the cellular localization of Ref-1 in human thyroid tumors was investigated. The Ref-1 immunodetection in normal thyroid tissue and thyroid adenomas, as well as in papillary, follicular and undifferentiated thyroid carcinomas is shown in Fig. 3. In normal thyroid tissue (five cases) follicular cells showed a strong nuclear staining. Ref-1 was also detectable in cytoplasm as dot-like structures; the intensity of the signal was much weaker than that detected in the nucleus. Thyroid adenomas showed a nuclear staining superimposable on that observed in normal tissue. However, no cytoplasmic signal was detected in three out of four cases investigated. In papillary (five cases), follicular (five cases) and undifferentiated thyroid carcinomas (four cases) the nuclear Ref-1 signal was less intense than that observed in normal thyroid. No difference could be detected in the cytoplasmic signal among normal tissue, follicular and undifferentiated carcinomas. In papillary carcinomas the cytoplasmic signal was particularly intense and homogeneously diffused. In order to quantitate the Ref-1 distribution in nuclear and cytoplasmic compartments, the ratio between Ref-1 nuclear-positive cells and Ref-1 cytoplasmic-positive cells was determined. Results are shown in Fig. 4. The nucleus/cytoplasm ratio was significantly lower in all histotypes of carcinomas compared with the normal tissue. No difference was detected among the different histotypes of cancer. Altogether, these results indicate that modification of the nuclear/cytoplasmic distribution of Ref-1 occurs in thyroid carcinomas.

\section{DISCUSSION}

Recent studies have demonstrated that redox potential-based mechanisms play a critical role in the regulation of transcription factors (Roy et al. 1997). Redox control of transcription factors is a 

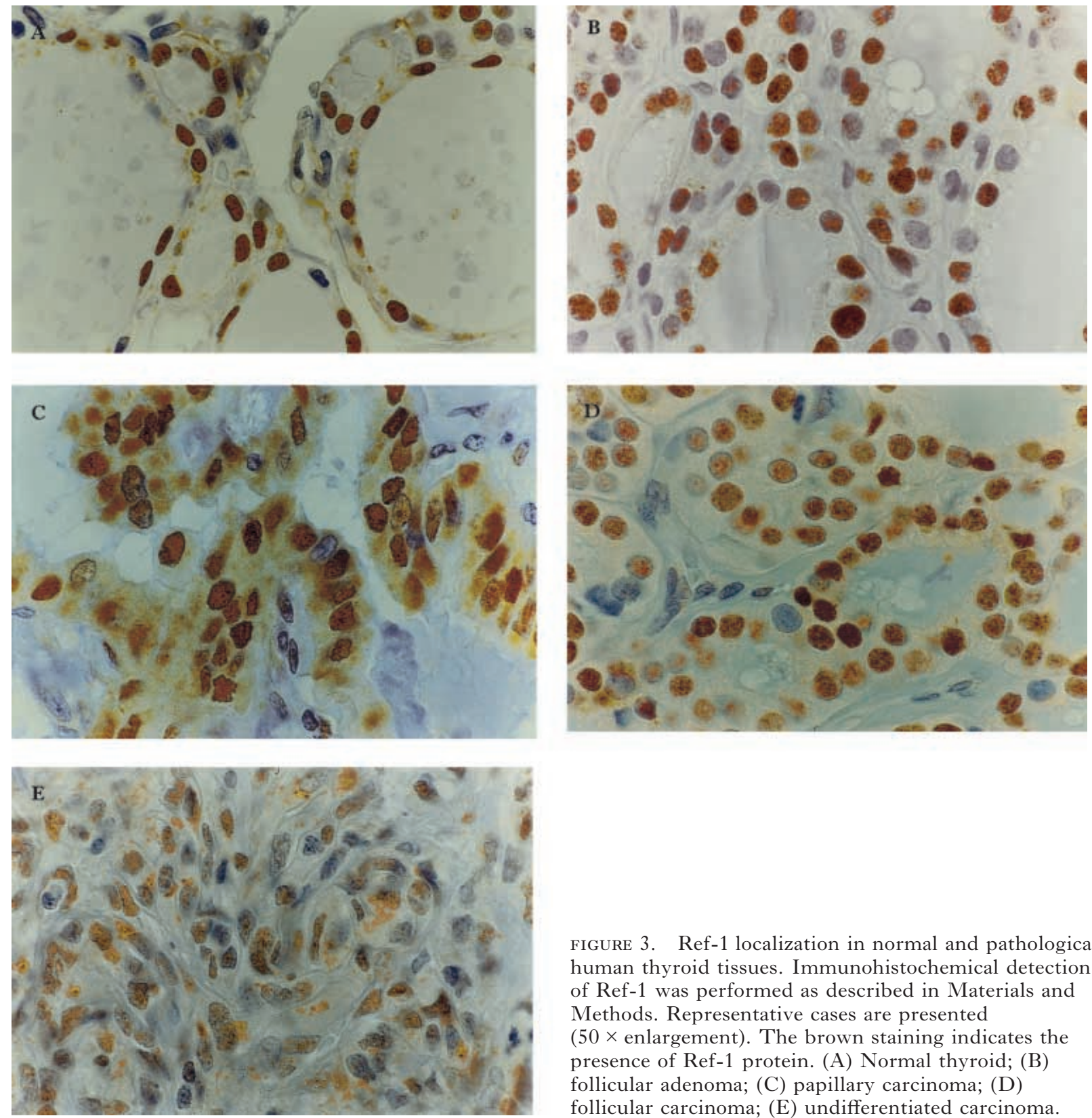

FIGURE 3. Ref-1 localization in normal and pathological human thyroid tissues. Immunohistochemical detection of Ref-1 was performed as described in Materials and Methods. Representative cases are presented $(50 \times$ enlargement). The brown staining indicates the presence of Ref-1 protein. (A) Normal thyroid; (B) follicular adenoma; (C) papillary carcinoma; (D) follicular carcinoma; (E) undifferentiated carcinoma.

fast and convenient way to regulate gene expression and provides the cell with the possibility of quickly reacting to external stimuli (Zheng et al. 1998). Redox regulation of transcription factors is largely based on the action of Ref-1 protein. Activation of transcription factors by this protein occurs through reduction of cysteine residues in the DNA-binding domain (Sen \& Packer 1996). Asai et al. (1997) have demonstrated that TSH increases Ref-1 protein levels in thyroid cells. In this study, we have solved

an apparent paradox. In fact, according to published data, the intracellular regulator, Ref-1, activates transcription factors through a fast mechanism (reduction of cysteine residues); however, the external signal, TSH, would activate the regulator through a time-consuming mechanism, neosynthesis of Ref-1. We have demonstrated that the first significant event of Ref-1 activation by TSH is the increase of cytoplasm-to-nucleus translocation, a fast mechanism in keeping with the high-speed 


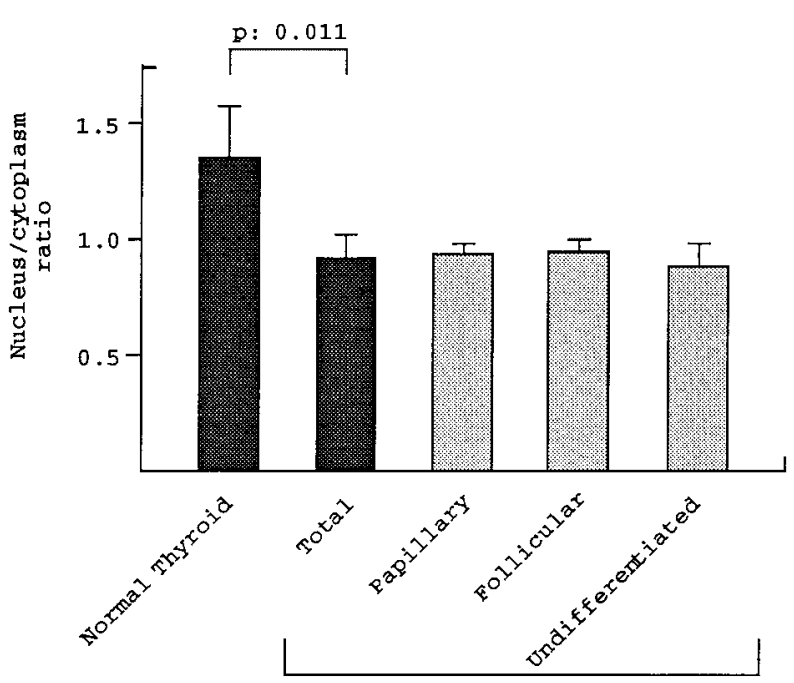

Thyroid carcinomas

FIGURE 4. Nucleus/cytoplasm positivity ratio in normal and pathological human thyroid tissues. Bars indicate the mean values and standard deviation of the ratios between nuclear-positive and cytoplasmic-positive cells in normal thyroid tissues and thyroid carcinomas.

'Total' indicates the value of the whole set of carcinomas. The significance between normal tissues and carcinomas was determined by a chi-square test.

mechanism by which Ref-1 activates transcription factors (reduction of cysteine residues). In this manner the redox signaling could rapidly modify thyroid gene expression.

In terms of transcriptional regulation, the present results should be coupled with those of our previous work (Tell et al. 1998b) where we demonstrated that Ref-1 overexpression is able to enhance the transcriptional activity of the thyroid-specific transcription factor, Pax8. In addition, it has been previously demonstrated that TSH induces prompt Pax8 activation through a rapid increase in its DNA-binding activity (Kambe et al. 1996). These authors suggested that the observed regulatory event would be due to thioredoxin, a cytoplasmic reducing enzyme. Here, we suggest that Ref-1 also could be involved in this rapid activation of Pax8.

Several data suggest that the cytoplasm-tonucleus translocation induced by TSH could have a role in turning on the neosynthesis of Ref-1 protein. In fact, it has been demonstrated that Ref-1 is able to induce c-jun DNA-binding activity (Xanthoudakis et al. 1992). Moreover, c-jun is a part of the multiprotein complex that activates Ref-1 promoter (Grösh \& Kaina 1999). Thus, one can envisage a simple model in which: (i) $\mathrm{TSH}$ enhances Ref-1 cytoplasm-to-nucleus translocation; (ii) nuclear Ref-1 induces c-jun DNA-binding activity; and (iii) a c-jun-dependent protein-DNA complex activates Ref-1 promoter activity upregulating Ref-1 protein synthesis. Accordingly, the total amount of Ref-1 protein present in FRTL-5 cells after long-term TSH treatment is much higher than that observed after short $(1 \mathrm{~h})$ hormonal stimulation (Tell et al. 1999b, and data not shown). By this mechanism, Ref-1-dependent transcriptional regulators can be turned on in a rapid fashion and then maintained on for an extended period of time.

In agreement with a previous investigation (Kakolyris et al. 1998), Ref-1 has been detected in both cytoplasm and nucleus in normal thyroid cells. Thyroid tumors do not show elevation of Ref-1 expression compared with normal tissue. On the contrary, increase of Ref-1 expression has been observed in cervical and germ cell tumors (Xu et al. 1997, Kelley et al. 1998). Compared with normal tissue, thyroid carcinomas show a reduced Ref-1 nucleus/cytoplasm immunoreactivity ratio. These results are reminiscent of those observed in epithelial ovarian cancer (Moore et al. 1999). It should be pointed out, however, that in normal ovaries only nuclear staining was observed in the absence of cytoplasm staining. Both nuclear and cytoplasmic staining was detected in ovarian tumors, but in the more aggressive ovarian cancers, the amount of cytoplasmic levels of APE/Ref-1 were dramatically increased and in $50 \%$ of cases the nucleus was 'cleared' of Ref-1. Therefore, while in ovarian tumors a qualitative change in Ref-1 localization occurs, in thyroid tumors only quantitative changes have been detected. The lack of difference between papillary, follicular and undifferentiated thyroid carcinomas would suggest that the modification of Ref-1 localization is not related to aggressiveness in thyroid tumors. At present, the functional significance of the altered Ref-1 distribution observed in thyroid carcinomas with respect to normal tissue is not clear. Because of the dual nature of Ref-1 (as regards its redox and repair activity) it would be interesting to investigate the two activities in the different cellular compartments to test whether the altered distribution observed in thyroid tumors may have a functional relevance. Unfortunately, processing of cell fractions from tissues would affect the Ref-1 activities.

Thyroid carcinogenesis is a multistage process with a sequence of specific gene mutations which stepwise increase the aggressiveness of the neoplasm (Williams 1995, Santoro et al. 1995, Wynford-Thomas 1997). For example, p53 gene mutation is present almost exclusively in poorly differentiated thyroid carcinomas (Ito et al. 1992, 
Fagin et al. 1993). In this light, the decrease of nuclear Ref-1 observed in differentiated carcinomas could reduce the DNA repair activity of the cell, facilitating the action of genotoxic agents, and thus progression toward a more aggressive phenotype. This hypothesis is supported by several observations indicating a direct relationship between the amount of nuclear Ref-1 and cell resistance to genotoxic agents (Walker et al. 1994, Tomicic et al. 1997, Grösh et al. 1998, Ludwig et al. 1998). To investigate the possibility that nuclear Ref-1 levels may protect cells from genotoxic agents we are selecting thyroid tumor cell lines differing from each other in the Ref-1 nuclear levels ( $G$ Tell \& $G$ Dahante, unpublished observations).

In conclusion, we have demonstrated that a modification of Ref-1 cellular compartmentalization occurs in thyroid carcinomas and that TSH controls the Ref-1 cytoplasm-to-nucleus translocation. In a previous investigation we have demonstrated that Ref-1 up-regulates the Pax 8 transcriptional activity (Tell et al. 1998b). Together, this evidence suggests that Ref-1 localization may have a critical role in the control of thyroid cell functions.

\section{ACKNOWLEDGEMENTS}

This work is funded by grants to $\mathrm{G} D$ from the Consiglio Nazionale dell Ricerche (CNR, Target Project on Biotechnology) and from Ministero dell' Università e della Ricerca Scientifica e Technologica. The authors thank $\mathrm{E}$ Tell for reviewing the English style.

\section{REFERENCES}

Ambesi-Imbiombato FS \& Coon HG 1979 Thyroid cells in culture. International Review of Cytology 10 163-172.

Asai T, Kambe F, Kikimori T \& Seo H 1997 Increase in Ref-1 mRNA and protein by thyrotropin in rat thyroid FRTL-5 cells. Biochemical and Biophysical Research Communications $23671-74$

Bradford MM 1976 A rapid and sensitive method for the quantitation of microgram quantities of protein utilizing the principle of protein-dye binding. Analytical Biochemistry $\mathbf{7 2}$ 248-254.

Fagin JA, Matsuo K, Karmakar A, Chen DL, Tang S-H \& Koeffler HP 1993 High prevalence of mutations of the p53 gene in poorly differentiated human thyroid carcinomas. Fournal of Clinical Investigation 91 179-184.

Gaiddon C, Moorthy NC \& Prives C 1999 Ref-1 regulates the transactivation and pro-apoptotic functions of p53 in vivo. EMBO Yournal 18 5609-5621.

Grösh S \& Kaina B 1999 Transcriptional activation of apurinic apyrimidinic endonuclease (Ape Ref-1) by oxidative stress requires CREB. Biochemical and Biophysical Research Communications 261 859-863.
Grösh S, Fritz G \& Kaina B 1998 Apurinic endonuclease (Ref-1) is induced in mammalians cells by oxidative stress and is involved in clastogenic adaptation. Cancer Research $\mathbf{5 8}$ $4410-4416$.

Ito T, Seyama T, Mizuno T, Tsuyama N, Hayashi T, Hayashi Y, Dohi K, Nakamura N \& Akiyama M 1992 Unique association of p53 mutations with undifferentiated but not with differentiated carcinomas of the thyroid gland. Cancer Research $\mathbf{5 2}$ 1369-1371.

Jayaraman L, Murthy KGK, Zhu C, Curran T, Xantoudakis S \& Prives C 1997 Identification of redox/repair protein Ref-1 as a potent activator of p53. Genes and Developments 11 558-570.

Kakolyris S, Kaklamanis L, Giatromanolaki A, Koukourakis M, Hickson ID, Barzilay G, Turley H, Leek RD, Kanavaros P, Georgulias V, Gatter KC \& Harris AL 1998 Expression and subcellular localization of human AP endonuclease 1 (HAP1/Ref-1) protein: a basis for its role in human disease. Histopathology 330 561-569.

Kambe F, Nomura Y, Okamoto T \& Seo H 1996 Redox regulation of thyroid transcription factors, $\mathrm{Pax}-8$ and TTF-1, is involved in their increased DNA-binding activities by thyrotropin in rat thyroid FRTL-5 cells. Molecular Endocrinology 10 801-812.

Kelley MR, Xu Y, Tritt R \& Robertson KA 1998 The multifunctional DNA base excision repair and redox protein, AP endonuclease (APE/ref-1), and its role in germ cell tumors. In Germ Cell Tumors IV, vol. 4, pp 81-86. Eds IAW Jones, P Harnden \& JK Joffe. London: John Libbey \& Co.

Ludwig DL, MacInnes MA, Takiguchi Y, Purtymun PE, Henrie M, Flannery M, Meneses J, Pedersen RA \& Chen DJ 1998 A murine AP-endonuclease gene-targeted deficiency with post-implantation embryonic progression and ionizing radiation sensitivity. Mutation Research 409 17-29.

Meira LB, Cheo DL, Hammer RE, Burns DK, Reis A \& Friedberg EC 1997 Genetic interaction between HAP1/REF-1 and p53. Nature Genetics 17145.

Moore DH, Michael H, Tritt R, Parsons S \& Kelley MR 2000 Alterations in the expression of the DNA repair/redox enzyme APE/Ref-1 in epithelial ovarian cancers. Clinical Cancer Research 2 602-609.

Nakamura H, Nakamura K \& Yodoi J 1997 Redox regulation of cellular activation. Annual Review of Immunology 15 351-369.

Ramana CV, Boldogh I, Izumi T \& Mitra S 1998 Activation of apurinic/apyridinic endonuclease in human cells by reactive oxygen species and its correlation with their adaptive response to genotoxicity of free radicals. Proceedings of the National Academy of Sciences of the USA 95 5061-5066.

Rothwell DG, Barzilay G, Gorman M, Morera S, Freemont P \& Hickson ID 1997 The structure and function of the HAP/Ref-1 protein. Oncology Research 9 275-280.

Roy D, Palangat M, Chen CW, Thomas RD, Colerangle J, Atkinson A \& Yan ZJ 1997 Biochemical and molecular changes at the cellular level in response to exposure to environmental estrogen-like chemicals. Fournal of Toxicology and Environmental Health 50 1-29.

Santoro M, Grieco M, Melillo RM, Fusco A \& Vecchio G 1995 Molecular defects in thyroid carcinomas: role of the ret oncogene in thyroid neoplastic transformation. European Fournal of Endocrinology 133 513-522.

Schreck R, Rieber P \& Bauerle PA 1991 Reactive oxygen intermediates as apparently widely used messengers in the activation of the NF-kappa B transcription factor and HIV-1. EMBO Fournal 10 2247-2258.

Sen CK \& Packer L 1996 Antioxidant and redox regulation of gene transcription. FASEB fournal 10 709-720. 
Tell G, Scaloni A, Pellizzari L, Formisano S, Pucillo C \& Damante G 1998 a Redox potential controls the structure and DNA-binding activity of the paired domain. Fournal of Biological Chemistry 273 25062-25072.

Tell G, Pellizzari L, Cimarosti D, Pucillo C \& Damante G $1998 b$ Ref-1 controls Pax-8 DNA-binding activity. Biochemical and Biophysical Research Communications 252 178-183.

Tomicic M, Eschbach E \& Kaina B 1997 Expression of yeast but not human apurinic/apyrimidinic endonuclease renders Chinese hamster cells more resistant to DNA damaging agents. Mutation Research 383 155-165.

Walker LJ, Craig RB, Harris AL \& Hickson ID 1994 A role for the human DNA repair enzyme HAP1 in cellular protection against DNA damaging agents and hypoxic stress. Nucleic Acids Research 22 4884-4889.

Ward JF 1994 The complexity of DNA damage: relevance to biological consequences. International Fournal of Radiation Biology 66 427-432.

Williams ED 1995 Mechanisms and pathogenesis of thyroid cancer in animals and man. Mutation Research 333 123-129.
Wynford-Thomas D 1997 Origin and progression of thyroid epithelial tumours: cellular and molecular mechanisms. Hormone Research 47 145-157.

Xanthoudakis S, Miao G, Wong F, Pan YCE \& Curran T 1992 Redox activation of fos-jun DNA binding activity is mediated by a DNA repair enzyme. EMBO Fournal 11 3323-3335.

Xanthoudakis S, Smeyne RJ, Wallace JD \& Curran T 1996 The redox/DNA repair protein, Ref-1, is essential for early embryonic development in mice. Proceedings of the National Academy of Sciences of the USA 93 8919-8923.

Xu Y, Moore D, Broshears J, Liu L, Wilson TM \& Kelley MR 1997 The apurinic apyrimidinic endonuclease (APE/ref-1) DNA repair enzyme is elevated in premalignant and malignant cervical cancer. Anticancer Research 37 $13-20$.

Zheng M, Aslund F \& Storz G 1998 Activation of the OxyR transcription factor by reversible disulfide bond formation. Science 279 1718-1721.

RECEIVED 28 October 1999 